\title{
Boas Práticas de Sustentabilidade em Canteiros de Obras
}

\author{
Ludimilla de Oliveira Zeule \\ Sheyla Mara Baptista Serra
}

\section{Introdução}

Ações e práticas sustentáveis podem ser entendidas em diferentes contextos. No âmbito da ação, Cavalcanti et al. (2012) propõem que a sustentabilidade pode ser uma estratégia fundamental para a preservação do ambiente, da cultura e da dignidade social das gerações. Já as práticas sustentáveis são um conjunto de ações inter-relacionadas, segundo Brasil (2016b), que resultam a médio e longo prazo numa nova perspectiva de vida para nossos sucessores ao garantir a manutenção dos recursos naturais necessários para uma melhor qualidade de vida.

Segundo Viggiano (2010), as ações sustentáveis podem ser classificadas de acordo com as diretrizes de sustentabilidade ambiental, social e econômica. De forma geral, indicam-se:

- Ações econômicas: necessitam da aplicação de capital e incentivo financeiro;

- Ações tecnológicas: subentendem o uso de equipamentos e tecnologias que proporcionem mais eficiência na busca da sustentabilidade;

- Ações sociais: tomadas junto aos trabalhadores e sociedade em geral, como treinamentos e campanhas de conscientização.

No caso do canteiro de obras, as ações sustentáveis podem ser transformadas em boas práticas que organizem e facilitem as tarefas diárias, não agridam o meio em 
que estão inseridos, utilizem alternativas oferecidas gratuitamente (água de chuva, insolação, ventos, iluminação) em benefício das atividades a serem realizadas, e ainda padronizem essas práticas para as obras seguintes (ZEULE, 2014).

A construção civil é um setor de grande potencial para a implantação de tecnologias sustentáveis, e as características dos empreendimentos têm contribuído para se disseminar o uso de programas de certificações sustentáveis. Segundo o órgão certificador Green Building Council Brasil (GBC BRASIL, 2015), existem atualmente, no Brasil, 279 edifícios certificados com o selo LEED (sigla, em inglês, para Leadership in Energy and Environmental Design), concedido pela entidade às construções que atendam a padrões de sustentabilidade. Para esse Conselho, o desenvolvimento da indústria da construção sustentável envolve a adoção de boas práticas e um processo integrado de concepção, construção e operação de edificações e de espaços construídos (GBC BRASIL, 2015).

Existem atualmente vários programas de selagem de certificação ambiental que se destacam por levar em conta práticas sustentáveis em todas as fases do empreendimento, considerando as fases de projeto, de execução e de ocupação. A implantação dos selos de certificação sustentável traz benefícios não apenas ambientais, mas econômicos e sociais. As construções que levam em conta os "critérios verdes" ganham com a diminuição de custos operacionais, melhora na saúde dos ocupantes, uso racional dos recursos naturais, entre outras vantagens (HALLIDAY, 2010).

Cada um dos selos ambientais possui características que orientam a seu favor a escolha feita pelas empresas na construção civil. Não há necessidade, contudo, do selo para que o canteiro de obras implemente práticas de sustentabilidade. Há, porém, a necessidade de que os métodos e práticas sejam mais divulgados para a sua efetiva implantação durante a fase de construção do empreendimento.

Segundo Costa e Moraes (2013), no Brasil as grandes construtoras perceberam que a aplicação de métodos de gestão sustentável durante todo o ciclo do empreendimento, inclusive durante a fase de construção, é a única maneira de garantir a melhoria do desempenho ambiental das edificações.

A proposta deste capítulo é exibir práticas e diretrizes de sustentabilidade em canteiros de obras nas quais as empresas da construção civil possam se basear e passem a adotá-las em seus canteiros, tornando-se assim empreendimentos sustentáveis nesta importante fase do processo de produção do empreendimento.

\section{Método de Pesquisa}

Este trabalho se baseia na dissertação de mestrado de Zeule (2014). A pesquisa utilizou o método de estudo de caso proposto por Yin (2009). A estratégia inicial de pesquisa consistiu em elaborar um quadro comparativo das diretrizes e regras de 
pontuações dos selos de certificações ambientais a fim de obter um formulário de avaliação da implementação da sustentabilidade em canteiro de obras. O quadro comparativo foi baseado em quatro programas de certificações - Building Research Establishment Environmental Assessement Method - BREEAM (BRE, 2009), Leadership in Energy and Environmental Design (LEED) for New Construction \& Major Renovation (LEED NC, 2009), Processo AQUA ${ }^{\circledR}$, baseado no selo francês HQE (Haute Qualité Environnementale) (FCAV, 2010), Selo Casa Azul da Caixa Econômica Federal (GUIA CAIXA, 2010). Além disso, as pesquisas de Cardoso e Araújo (2007) e de Brandão (2011) serviram como referência de práticas sustentáveis em canteiro de obras.

Foram visitados seis canteiros de obras brasileiros, localizados nos estados de São Paulo e do Ceará, sendo três obras certificadas ambientalmente e quatro obras definidas como Empreendimentos de Habitação Social (EHIS), com a intenção de analisar a viabilidade e aplicabilidade do método proposto por Zeule (2014).

Os critérios de avaliação da sustentabilidade foram divididos em seis níveis, de acordo com a organização do LEED, e as perguntas da lista de verificação foram baseadas nas recomendações dos programas de certificações para pontuação das práticas no canteiro. As práticas de sustentabilidade foram classificadas em: Canteiro Sustentável, Uso Racional da Água, Uso Racional de Energia, Materiais e Recursos, Qualidade do Ambiente, Inovações e Processos, e estão detalhadas a seguir. Ao final da aplicação da lista de verificação em cada canteiro de obras, foi possível obter um nível comparativo de nota de implantação da sustentabilidade (ZEULE, 2014).

\section{Práticas de Sustentabilidade no Canteiro de Obras}

A adoção de várias práticas ajuda a caracterizar um canteiro sustentável, e o conhecimento das possibilidades ajuda a tornar a sustentabilidade do empreendimento um fato.

\subsection{Canteiro Sustentável}

Deve-se pensar em premissas básicas de sustentabilidade que sejam possíveis de serem atendidas por qualquer obra, cobrindo várias etapas do empreendimento, desde a compra do terreno, escolha de materiais, preservação de vegetações existentes, entre outras.

Os itens a serem avaliados em um canteiro sustentável são: 1) Adequação de transporte; 2) Redução de ilhas de calor e priorização do conforto térmico; 3) Evitar emissão de particulados; 4) Preservação da vegetação nativa; 5) Seleção responsável do terreno. 
Neste sentido, as práticas de sustentabilidade recomendadas são listadas a seguir.

1) Adequação de transporte: voltado ao transporte de trabalhadores, entrega de materiais e componentes e logística interna no canteiro:

- Estabelecer fretamento de ônibus particular para buscar e levar os trabalhadores;

- Disponibilizar vale transporte, quando a medida anterior não for possível;

- Aumentar a demanda por materiais de construção e produtos que são extraídos e produzidos na região;

- Minimizar os transportes dentro do canteiro para reduzir a poluição e impactos causados pelo uso do automóvel;

- Criar estacionamento adequado para veículos leves;

- Separar vias de pedestres e veículos leves e pesados (Figura 1).

- Criar local com guarita e pavimentação para entrega de materiais;

- Criar local para bicicletário (Figura 2a);

2) Redução de ilhas de calor e priorização do conforto térmico: melhoria das condições de permanência dos trabalhadores dentro do canteiro, preservação ou construção de espaços verdes:

- Deixar uma área descoberta (se possível), sombreada e ventilada para uso comum dos trabalhadores do canteiro junto às demais áreas de vivência;

- Instalar janelas e aberturas nos refeitórios e demais instalações provisórias do canteiro que garantam ventilação e iluminação adequada;

- Construir as instalações provisórias preferencialmente com materiais reciclados, porém livres de Compostos Orgânicos Voláteis (COV) e que forneçam devido conforto térmico;

- Utilizar materiais isolantes térmicos em fachadas e coberturas das instalações, se necessário;

- Utilizar materiais de alta refletância solar, priorizando cores claras;

- Fazer uso de telhado verde e calçadas verdes para redução de ilhas de calor (Figura 2b).

3) Evitar emissão de particulados: estratégias para redução da emissão de poeiras no canteiro e vizinhanças:

- Empregar lava-rodas utilizando água de chuva (Figura 3);

- Empregar lava-bicas utilizando água de chuva (Figura 3); 
- Fazer a recuperação de águas do lava-rodas, bicas, ralos para posterior uso, como para irrigação do canteiro e diminuição da poeira;

- Implantar sistema simplificado de captação de água de chuva para lavagem de equipamentos e irrigação do canteiro;

- Fazer a limpeza umidificada diária nos ambientes de trabalho, de preferência com águas reaproveitadas.

4) Preservação da vegetação nativa: principalmente quando for prevista a manutenção da vegetação durante a fase de ocupação do empreendimento:

- Preservar as árvores e vegetações nativas que existiam anteriormente no terreno (Figura 4).

5) Seleção responsável do terreno: observação dos parâmetros urbanísticos e ambientais relacionados com o terreno:

- Manter o terreno de acordo com a proposta de gestão ambiental da obra;

- Verificar se o terreno não está inserido em zona de proteção ambiental. Se estiver, deve-se verificar se atende às leis correspondentes;

- Atender ao plano diretor municipal;

- Verificar se o solo foi ou está contaminado e realizar, se necessário, processo de recuperação antes da construção;

- Realizar sondagem do terreno;

- Realizar, registrar e acompanhar durante toda a construção o relatório de impacto do empreendimento sob a vizinhança.

As Figuras 1, 2, 3 e 4 a seguir exibem imagens de canteiros com algumas das práticas citadas anteriormente.

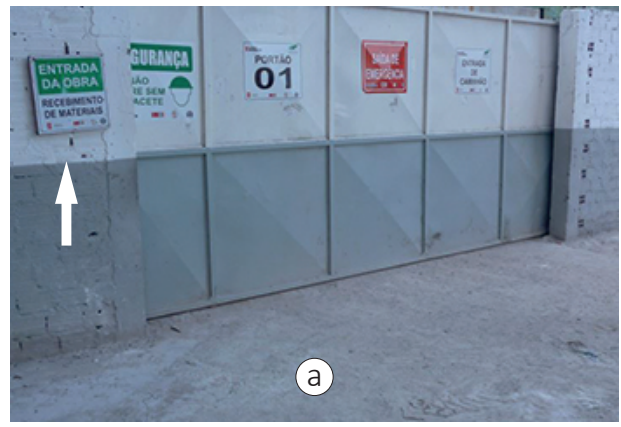

Entrada somente para

"Recebimento de materiais" como diz na placa

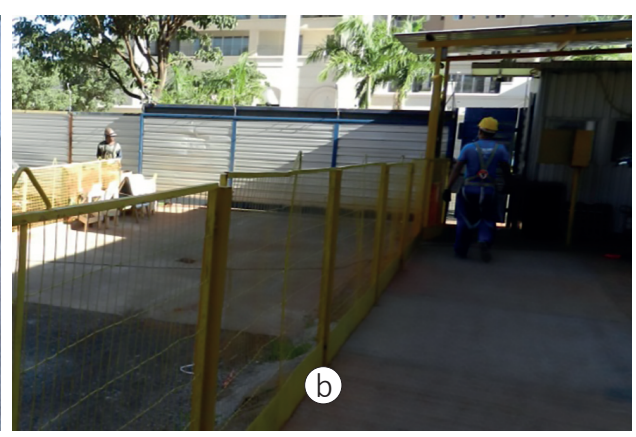

Entrada de veículos (leves e pesados) à esquerda e de pessoas à direita separação das vias por guarda-corpos

Figura 1 - Separação de vias para entrada no canteiro. Fonte: Autoras (2016). 


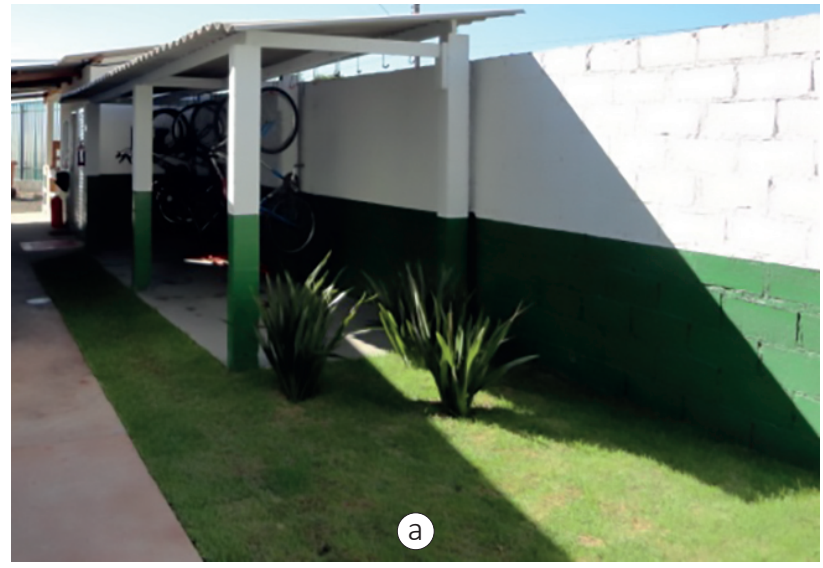

Implementação de bicicletário

e área verde ao redor

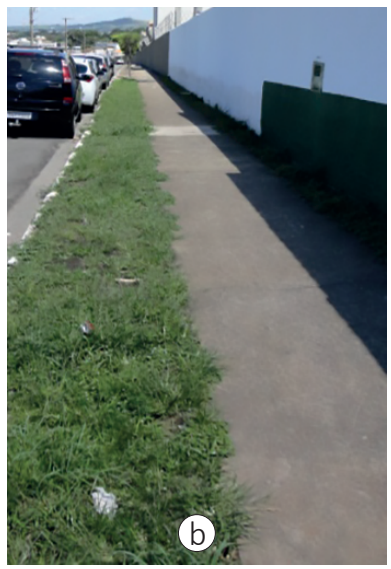

Calçada verde no entorno de toda a obra

Figura 2 - Implementação de bicicletário e áreas verdes. Fonte: Zeule (2014).

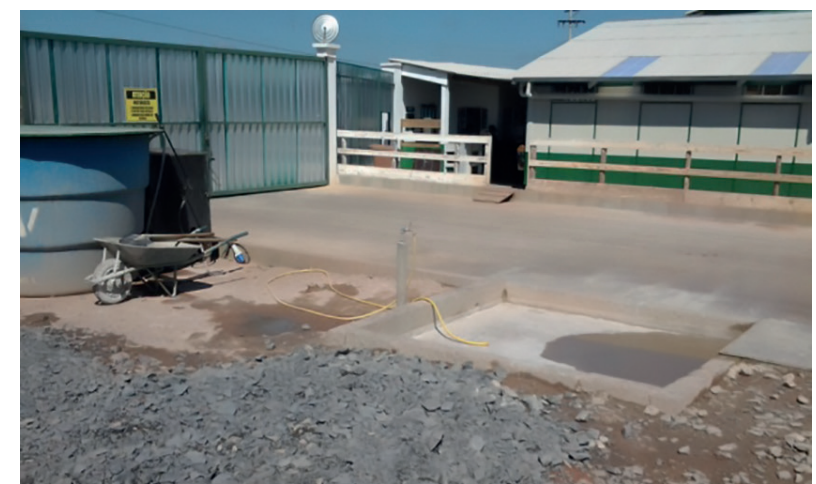

Figura 3 - Local para lavagem de rodas e bicas dos caminhões. Fonte: Zeule (2014).

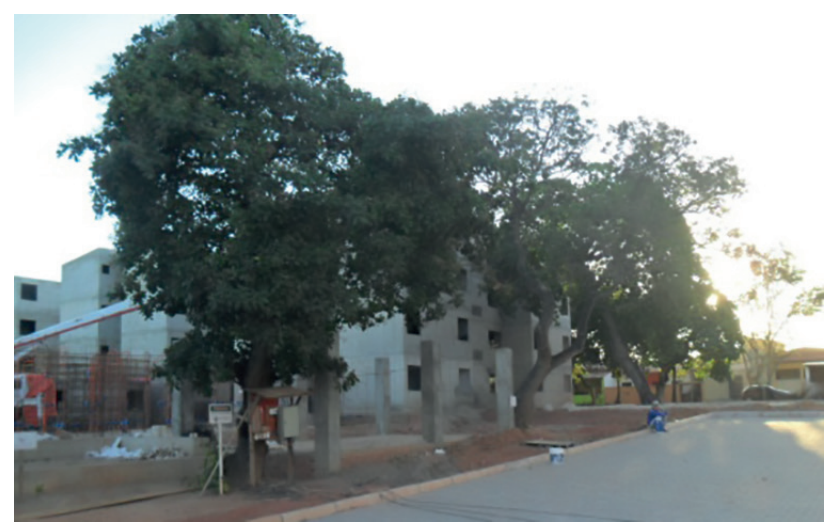

Figura 4 - Preservação da vegetação nativa existente no canteiro. Fonte: Zeule (2014). 


\subsection{Uso Racional da Água}

As possibilidades de uso racional da água dentro do canteiro de obra muitas vezes são desprezadas, gerando enormes desperdícios. Sabe-se que a água é um recurso finito e é muito utilizada em várias atividades diárias do canteiro, sendo necessária a inserção de práticas de sustentabilidade para que seu uso seja mais eficiente e econômico.

Observa-se que existem algumas pesquisas e orientações para o uso de estratégias de minimização e controle do consumo da água dentro dos canteiros de obras. Entretanto, ainda não há implantação massiva nos canteiros de obra, devido talvez ao desconhecimento e à falta de incentivo das normalizações.

De acordo com a Norma Regulamentadora 18 - Condições e Meio Ambiente de Trabalho na Indústria da Construção (NR-18), que descreve as "Condições e Meio Ambiente de Trabalho na Indústria da Construção" (BRASIL, 2015), a utilização de água nos canteiros de obras está relacionada às demandas essenciais dos funcionários e devem estar presentes nos itens básicos: a) refeitórios; b) instalações hidrossanitárias; c) bebedouros. De modo geral, a água também deve estar presente nas frentes de trabalho para atender as demandas das atividades e serviços.

Entre as principais práticas encontradas na literatura estão: 1) Captação de água pluvial e cinza e consequente tratamento para reutilização em canteiro; 2) Tecnologias utilizadas para águas servidas em canteiros; 3) Redução do consumo de água.

A seguir, são listadas as práticas aplicáveis aos canteiros para uso racional da água.

1) Captação de água pluvial e cinza e consequente tratamento para reutilização em canteiro

- Realizar captação de águas cinzas (pias e chuveiros) e de chuva (pluviais) (Figura 5a);

- Fazer o correto tratamento das águas a serem reutilizadas;

- Observar se as águas captadas (pluviais e/ou cinzas) foram corretamente tratadas para posterior reuso;

- Manter as tubulações e os dispositivos de coleta de água de chuva totalmente separados das instalações de água potável;

2) Tecnologias utilizadas para águas servidas em canteiros: para fins de separação e reuso, as águas servidas compõem-se das águas negras (vasos sanitários e pias de cozinha) e águas cinzas (chuveiros, lavatórios de banheiro, tanques):

- Prever sistema para escoamento das águas negras da obra;

- Estabelecer manutenção periódica das instalações de águas servidas; 
3) Redução do consumo de água: prever a instalação de dispositivos e estratégias de conscientização:

- Instruir os trabalhadores nas formas de gerar economia de água por meio de cursos de conscientização ou orientações por escrito (Figura 6);

- Utilizar equipamentos redutores de consumo de água nas instalações provisórias, como torneiras com fechamento automático, caixa de descarga com capacidade menor que 6 litros, redutor de pressão, arejador etc.;

A seguir, as Figuras 5 e 6 exibem imagens de canteiros com algumas das práticas citadas anteriormente.

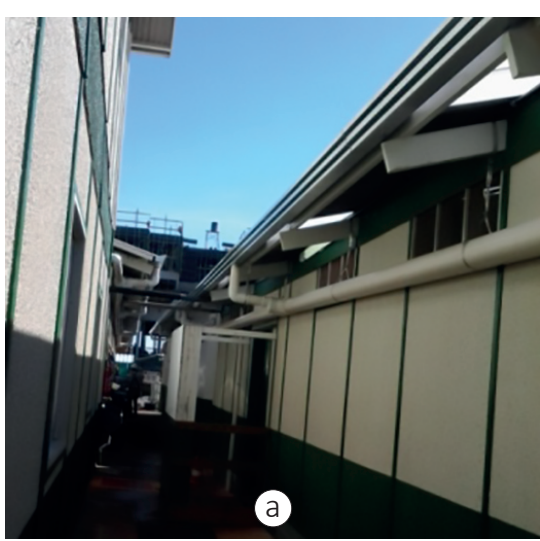

Sistema de Captação de água pluvial (chuva) pelo telhado nas instalações provisórias

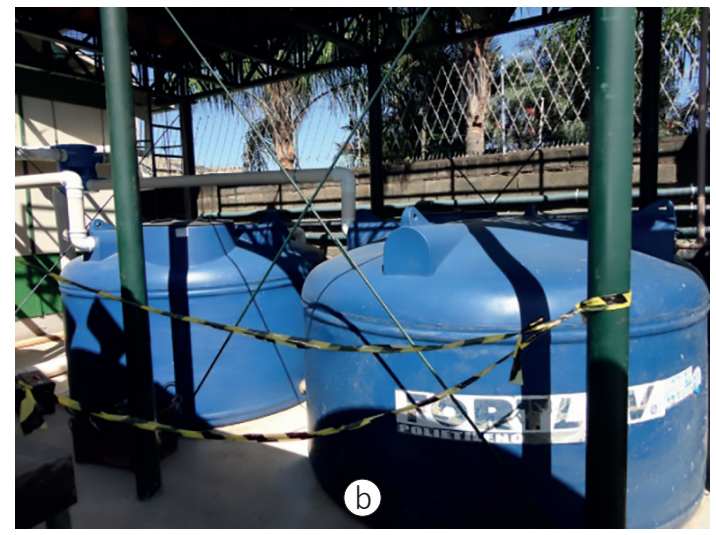

Sistema para tratamento da água de pluvial para reuso no próprio canteiro

Figura 5 - Captação e tratamento de água pluvial e economia de água. Fonte: Zeule (2014).

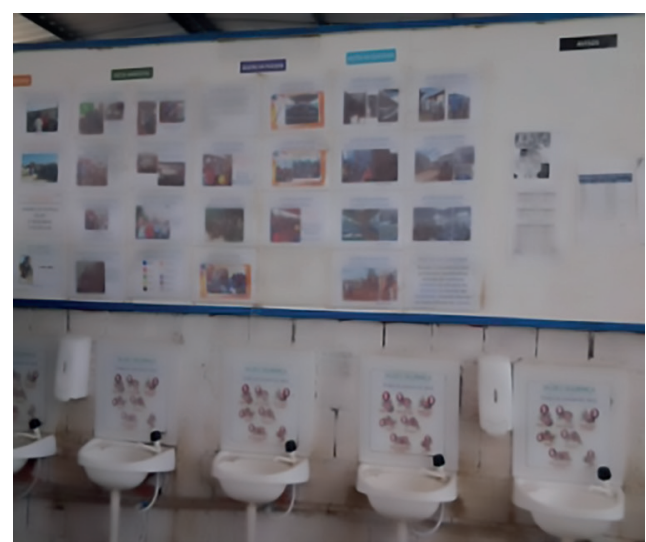

Figura 6 - Instruções aos trabalhadores para economizar água e cuidados com a saúde e segurança no trabalho. Fonte: Zeule (2014). 


\subsection{Uso Racional da Energia}

Esse item incentiva o uso de energias renováveis no canteiro, oferecendo conforto aos operários, reduzindo a emissão de ruídos e melhorando o uso dos vestiários, a fim de propiciar o bem-estar dos trabalhadores e a economia de energia elétrica.

Dessa forma, as práticas elencadas com relação ao uso racional da energia no canteiro de obras são: 1) Geração local de energia renovável; 2) Tecnologias para redução do consumo de energia. As diretrizes para essas práticas são listadas a seguir.

1) Geração local de energia renovável: dependendo da localização geográfica e disponibilidade, verificar a existência de outros tipos de energia:

- Fazer uso de energias renováveis disponíveis: eólica, solar, geotérmica, fotovoltaica;

2) Tecnologias para redução do consumo de energia:

- Priorizar o uso de iluminação e ventilação natural nas instalações provisórias do canteiro (Figura 7);

- Fazer a medição do consumo de energia, visando ao controle e à redução deste consumo;

- Evitar o uso de geradores de energia;

- Utilizar lâmpadas etiquetadas com selo PROCEL/INMETRO;

- Utilizar equipamentos economizadores e com selo PROCEL de eficiência energética;

- Instalar sensores de presença em ambientes de passagem rápida, nos quais normalmente se esquece a luz acesa.

A Figura 7, a seguir, exibe imagens de canteiros com algumas das práticas citadas anteriormente.

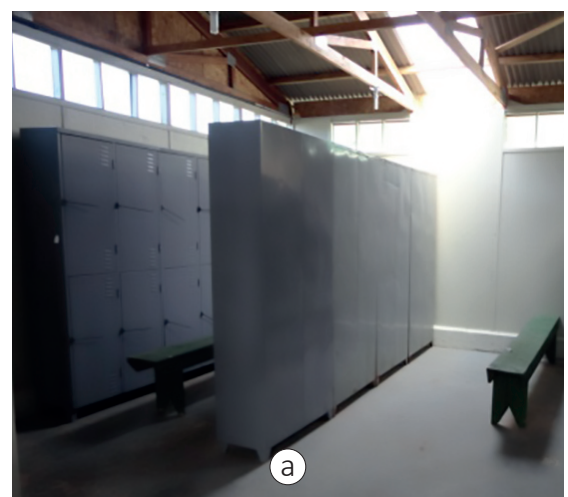

Iluminação e ventilação natural no vestiário

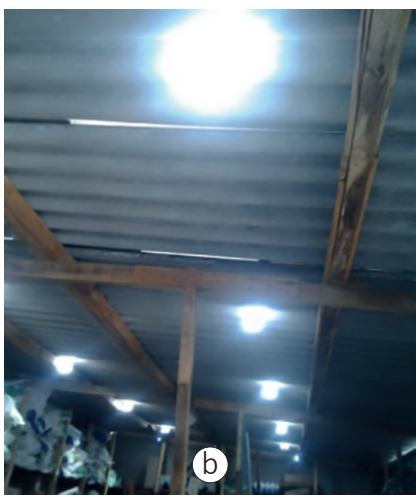

Alternativa para economia de energia, com garrafas PET com água no lugar de lâmpadas

Figura 7 - Iluminação natural nas instalações provisórias. Fonte: Zeule (2014). 


\subsection{Materiais e Recursos}

A gestão e logística de materiais e recursos dentro do canteiro de obras são de suma importância, uma vez que lidam com a disposição adequada dos materiais que serão utilizados durante toda a fase de execução. Não menos importante é a deposição adequada dos resíduos e seus reusos no próprio canteiro. No canteiro, são gerados vários tipos de resíduos além do resíduo da construção, normalmente conhecido como entulho.

Sob estes aspectos, definiu-se que os fatores importantes de serem avaliados no canteiro referentes ao assunto são: 1) Realização de depósito e coleta para materiais recicláveis; 2) Gestão dos resíduos da construção; 3) Reuso de materiais; 4) Uso de madeira certificada.

A seguir, são apresentadas as diretrizes com as práticas relacionadas.

1) Realização de depósito e coleta para materiais recicláveis:

- Estabelecer baias de separação por tipo de resíduo (Figura 8a);

- Separar os resíduos contaminantes (classe D) dos demais (Figura 8b);

- Separar lixo orgânico do inorgânico;

- Praticar a coleta seletiva em todos os empreendimentos da empresa;

- Proteger os estoques de materiais contra intempéries;

- Armazenar os materiais conforme orientações das normas técnicas e dos fabricantes.

2) Gestão dos resíduos da construção:

- Priorizar o uso de materiais passíveis de reciclagem;

- Controlar a entrada de materiais no canteiro;

- Realizar inspeção de produtos conformes e não conformes no ato da entrega;

- Especificar produtos tóxicos e acondicioná-los isolados do solo;

- Fazer controle de utilização de produtos/materiais por prazo de validade;

- Manter o local de armazenamento de resíduos bem iluminado e ventilado, com pontos de água, tubulação de esgoto e ralo sifonado;

- Criar um programa de bonificação aos trabalhadores que reduzirem a geração e quantidade de resíduos.

3) Reuso de materiais:

- Utilizar materiais sustentáveis e reciclados que sejam livres de Compostos Orgânicos Voláteis (COV) sempre que possível (Figura 9a);

- Reaproveitar materiais que seriam descartados para outros fins (Figura 9b); 
- Reutilizar materiais, por exemplo, argamassa e cimento endurecido, que podem ser triturados e virar cascalho para vias.

\section{4) Uso de madeira certificada:}

- Ter controle de todas as madeiras utilizadas, verificando os certificados de conformidade;

- Utilizar madeiras recicladas livres de Compostos Orgânicos Voláteis e outros produtos químicos.

As Figuras 8 e 9 a seguir exibem imagens de canteiros com algumas das práticas citadas anteriormente.

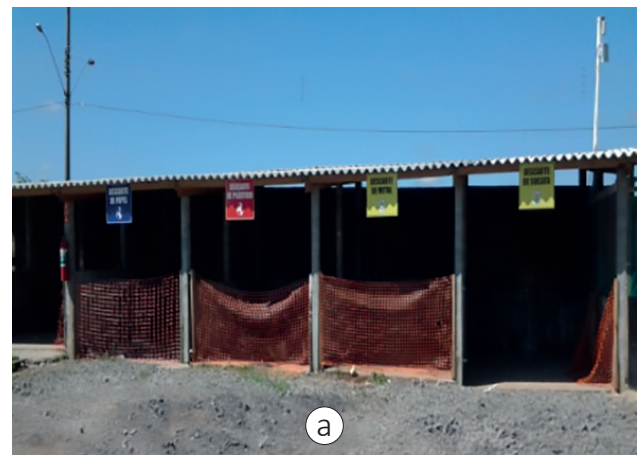

Baias cobertas para separação dos vários tipos de resíduos

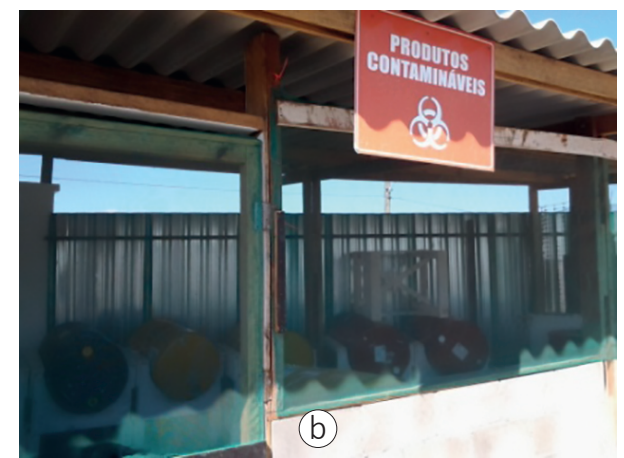

Acondicionamento de produto contaminante, afastado do solo

Figura 8 - Acondicionamento de resíduos no canteiro de obras. Fonte: Zeule (2014).

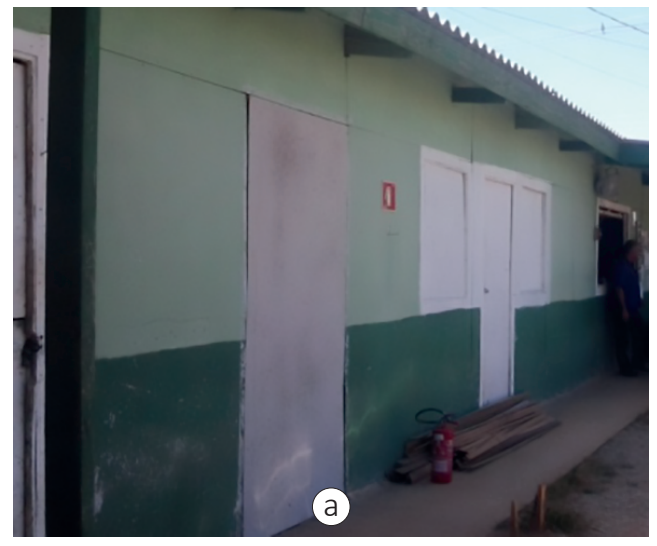

Instalação provisória feita com chapas de madeira reciclada

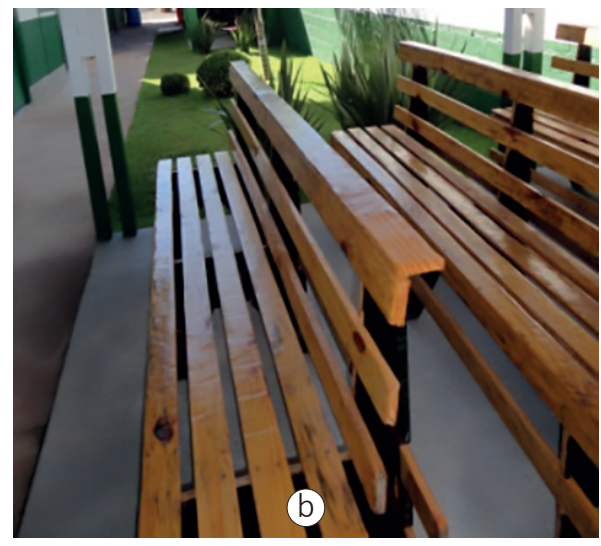

Reuso de madeira de formas

Figura 9 - Uso de materiais reciclados e reuso de materiais que seriam descartados. Fonte: Zeule (2014). 


\subsection{Qualidade do Ambiente}

A qualidade do ambiente está relacionada diretamente às necessidades e conforto dos trabalhadores e usuários do canteiro de obras, sendo considerados na análise desse item todos os ambientes destinados às atividades dos operários e a existência dos confortos olfativo, térmico, acústico e visual presentes nos canteiros de obras.

Definiu-se que os fatores importantes a serem avaliados no canteiro referentes ao assunto são: 1) Conforto aos usuários do canteiro e entorno; 2) Redução nas emissões de Cloro-Flúor-Carbono (CFC's) e Dióxido de Carbono $\left(\mathrm{CO}_{2}\right)$.

As principais boas práticas identificadas são listadas a seguir.

1) Conforto aos usuários do canteiro e entorno:

- Manter o canteiro de obras livre de odores prejudiciais à saúde dos usuários (por exemplo, produtos tóxicos exalantes);

- Preservar os ambientes salubres de acordo com orientações da NR-18 Condições e Meio Ambiente de Trabalho na Indústria da Construção (BRASIL, 2015);

- Controlar e minimizar as fontes de poluição;

- Criar um "fumódromo" - local específico para consumo do tabaco;

- Manter o entorno (ruas e calçadas) do canteiro limpo (Figura 10b);

- Garantir que os portões de acesso à obra sejam monitorados por câmeras ou vigias;

- Verificar se o local oferece conforto térmico aos usuários, mantendo locais bem dimensionados sombreados e ventilados, áreas verdes, espelhos d'água;

- Verificar se o local oferece conforto visual, apresentando-se limpo e organizado;

- Verificar se o local oferece conforto acústico aos usuários e entorno, observando o uso correto de equipamentos de proteção coletiva (EPI), a localização adequada de equipamentos, a existência de máquinas que emitam menores ruídos e vibrações etc.;

- Preservar as instalações provisórias em boas condições de uso e ocupação, conforme NR-18 - Condições e Meio Ambiente de Trabalho na Indústria da Construção (BRASIL, 2015);

- Projetar as instalações provisórias com tecnologias e dispositivos passíveis de desmontagem e reutilização, mantendo-se as boas condições;

- Limpar os banheiros e refeitórios diariamente (Figura 10a);

2) Redução nas emissões de Cloro-Flúor-Carbono (CFC's) e Dióxido de Carbono $\left(\mathrm{CO}_{2}\right)$

- Realizar os procedimentos de neutralização de carbono quando se fizer uso de produtos/equipamentos emitentes de $\mathrm{CFC} / \mathrm{CO}_{2}$; 
- Conservar os equipamentos de uso nas instalações provisórias, tais como geladeiras e ar condicionados, com menos de cinco anos de uso;

- Realizar manutenção periódica nos veículos e maquinários de uso no canteiro.

A Figura 10 a seguir exibe imagens de canteiros com algumas das práticas citadas anteriormente.

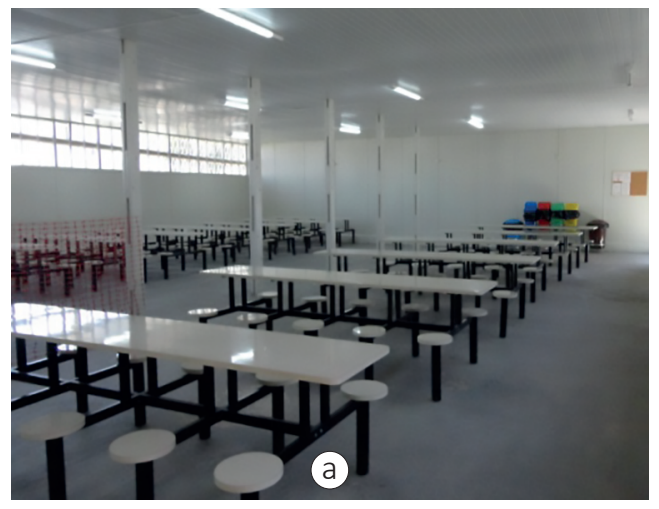

Refeitório em perfeitas condições de uso e limpeza

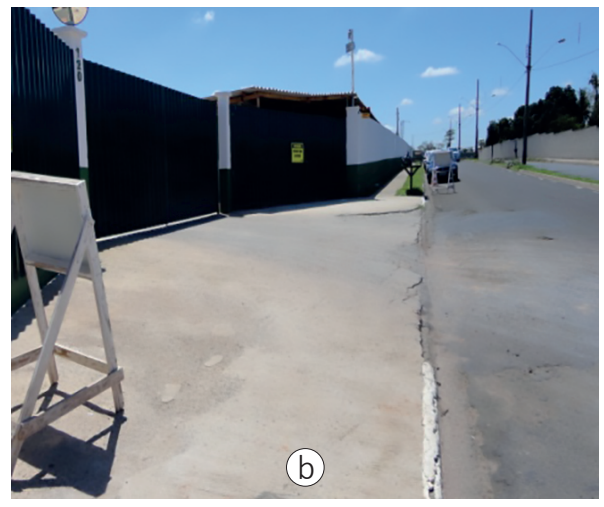

Entorno da obra

(ruas e calçadas) limpas

Figura 10 - Práticas relacionadas à qualidade do ambiente do canteiro. Fonte: Zeule (2014).

\subsection{Inovações e Processos}

Considera-se inovações gerenciais e tecnológicas aquelas que podem ser inseridas no canteiro, como a bonificação paga aos trabalhadores por incentivo à produção, a possibilidade de customização (isto é, permissão para mudança nos ambientes de acordo com os desejos dos futuros usuários), industrialização de equipamentos e materiais etc. (ZEULE, 2014).

A seguir, são apresentadas as diretrizes para cumprimento desse ponto de avaliação.

1) Inovações e processos:

- Organizar um plano de chegada de caminhões (evitando que fiquem estacionados nas vizinhanças da obra, causando incômodos à vizinhança e grande interferência no tráfego local);

- Verificar se os veículos utilizados na obra estão com os impostos pagos, principalmente no caso deles não serem da empresa executante; 
- Verificar também se existe controle de manutenção individual por veículo ou equipamento de obra;

- Certificar-se da qualificação da mão de obra e fornecedores contratados;

- Verificar se a mão de obra está apta ao serviço e se realizou treinamento;

- Não realizar queima de materiais em canteiro;

- Prever área para instalação da caixa de decantação de águas de lavagem de equipamentos como betoneira, argamassadeira, caminhão betoneira (Figura 11);

- Fazer uso de materiais industrializados pensando na eliminação de processos internos ao canteiro (argamassa industrializada, argamassa projetada, concreto usinado, concreto autoadensável, gesso projetado, gesso acartonado, sistema flexível de tubulação, guinchos ou gruas, lajes nervuradas, entre outros) (Figura 12);

- Elaborar plano de prevenção de riscos ambientais orientada pela NR-9 Programa de Prevenção de Riscos Ambientais (BRASIL, 2016a) (Figura 13);

- Manter registro e implantar programa de segurança no trabalho específico para construção- o Programa de Condições e Meio Ambiente de Trabalho na Indústria da Construção (PCMAT), disposto na NR-18 - Condições e Meio Ambiente de Trabalho na Indústria da Construção (BRASIL, 2015);

- Registrar os impactos ambientais e desempenho dos materiais e produtos durante seu processo de aquisição.

As Figuras 11 a 13 a seguir exibem imagens de canteiros com algumas das boas práticas citadas anteriormente.

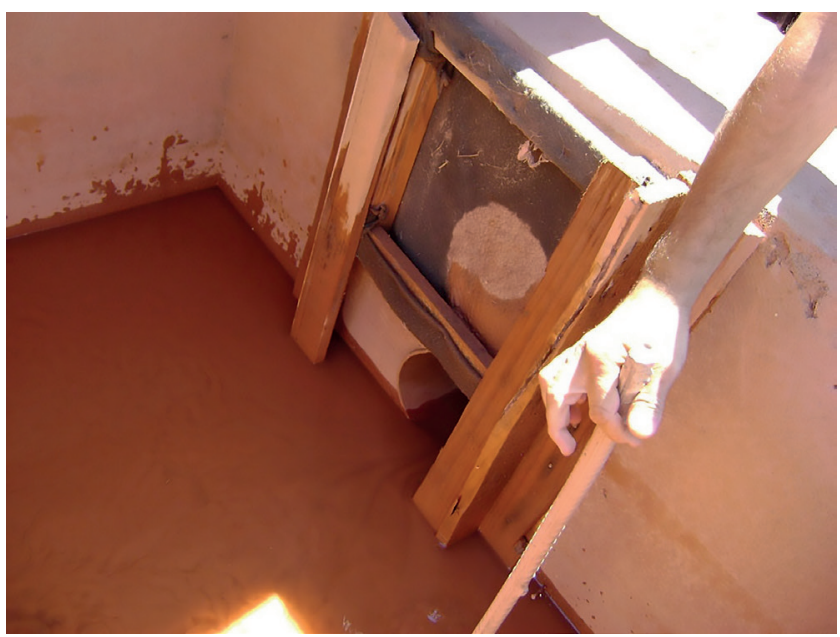

Figura 11 - Caixa de decantação da água com material particulado instalada no terreno. Fonte: Autoras (2016). 


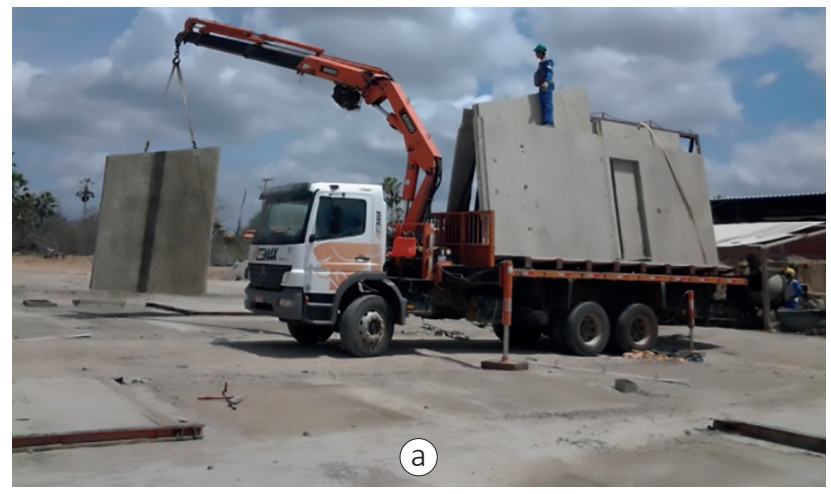

Uso de painéis pré-moldados de concreto sendo içados, eliminando vedações com blocos

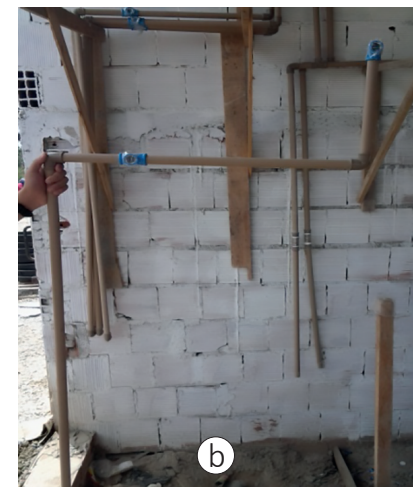

Kits de tubulações de água fria prontas para serem instaladas nos painéis pré-moldados

Figura 12 - Práticas para eliminação e simplificação de processos produtivos no canteiro. Fonte: Zeule (2014).

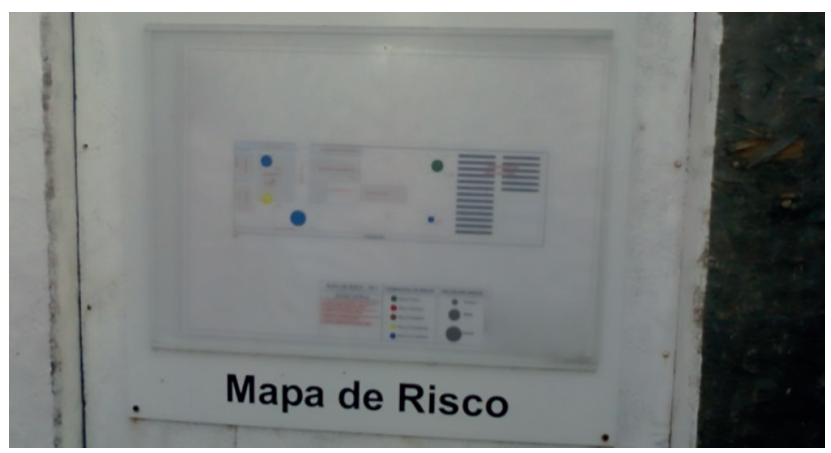

Figura 13 - Fixação do Mapa de Riscos (NR-9 - Programa de Prevenção de Riscos Ambientais) em Canteiro de Obra. Fonte: Autoras (2016).

\section{Conclusões}

A implantação das boas práticas apresentadas neste trabalho auxiliarão as empresas na adoção de estratégias modernas de gestão, com a incorporação de aspectos de sustentabilidade e responsabilidade social. Além de muitas das práticas terem valores significativamente baixos para implantação, os retornos do investimento podem ser intangíveis, como a melhoria da imagem e a comparação com empresas concorrentes.

É recomendado que as empresas de construção de edificações busquem alternativas que atuem na redução de impactos ambientais e adotem ferramentas 
gerenciais, como a implantação de um sistema de gestão ambiental. O planejamento antecipado aplicado à construção civil contribui para minimização dos impactos gerados pelas edificações, principalmente na fase de produção da construção, já que o canteiro de obras é uma fase considerada como grande causadora de danos ao meio ambiente.

Este estudo permitiu identificar a influência que a fase de execução (canteiro de obras) tem sobre o empreendimento como um todo, avaliando as diversas ocorrências de possibilidade de implantação das boas práticas de sustentabilidade.

Os órgãos públicos e financiadores das Habitações de Interesse Social (HIS) precisam ser mais contundentes em orientar a adoção de tais práticas, visto que existem vários empreendimentos desse tipo em todo o país e as práticas adotadas por eles refletem em grande porcentagem o setor da construção civil, trazendo benefícios para toda a sociedade.

Por fim, recomenda-se como necessária a obtenção de indicadores de sustentabilidade em empreendimentos, visando, além de uma mudança atual da construção civil, à melhoria nos processos produtivos, ao desenvolvimento tecnológico na fabricação dos materiais e componentes e à conscientização e treinamento de pessoal técnico e operacional.

\section{Referências}

BRANDÃO, G.B.M. Tecnologias e Certificações para Canteiros Sustentáveis. 2011. $66 f$. Trabalho de Conclusão de Curso. Engenharia Civil. Universidade Federal de São Carlos, São Carlos.

BRASIL. Ministério do Trabalho e Emprego. Norma Regulamentadora 18 (NR-18): Condições e meio ambiente de trabalho na indústria da construção. 2015. Brasília-DF. Disponível em: <http://trabalho.gov.br/seguranca-e-saude-no-trabalho/normatizacao/ normas-regulamentadoras/norma-regulamentadora-n-18-condicoes-e-meio-ambientede-trabalho-na-industria-da-construcao>. Acesso em: nov. 2016.

BRASIL. Ministério do Trabalho e Emprego. Norma Regulamentadora 9 (NR-9): Programa de Prevenção de Riscos Ambientais. 2016a. Brasília-DF. Disponível em: <http://trabalho. gov.br/images/Documentos/SST/NR/NR09/NR-09-2016.pdf >. Acesso em: nov. 2016.

BRASIL. Sustentável. Economia e meio ambiente no Brasil: Sustentabilidade. 2016b. Disponível em: <http://www.brasilsustentavel.org.br/sustentabilidade>. Acesso em: nov. 2016.

BRE. British Research Establishment Environment. Assessement Method (BREEAM). EuropeCommercial 2009 Assessor. Manual. BRE Global Ltda., 346 p. 2009.

CARDOSO, F.F.; ARAUJO, V.M. Levantamento do estado de arte: Canteiro de obras. Projeto Finep: Tecnologias para construção habitacional mais sustentável. São Paulo, 38p. 2007. 
CAVALCANTI, A.L.B.L.; PRETO, S.C.S.; PEREIRA, F.A.F.; FIGUEIREDO, L.F.G. Design para a Sustentabilidade: um conceito interdisciplinar em construção. Projética Revista Científica de Design, Londrina, v. 3, n. 1, julho, 2012.

COSTA, E.D.; MORAES, C.S.B. Construção civil e a certificação ambiental: análise comparativa das certificações LEED (Leadership in Energy and Environmental Design) e AQUA (ALTA Qualidade Ambiental). Engenharia Ambiental, Espírito Santo do Pinhal, v. 10, n. 3, p. 160-177, maio/jun. 2013.

FCAV. Fundação Carlos Alberto Vanzolini. Referencial técnico de certificação: edifícios do setorde serviços - processo AQUA. Francisco Ferreira Cardoso (coord.), São Paulo, 2010.

GBC BRASIL. Green Building Council Brasil. Certificação sustentável ganha espaço nos imóveis residenciais. Publicado em: out. 2015. Disponível em: <http://gbcbrasil.org.br/ detalhe-noticia.php?cod=130>. Acesso em: nov. 2016.

GUIA CAIXA. Selo Casa Azul: Boas práticas para habitação mais sustentável. Sustentabilidade Ambiental. JOHN, V.M.; PRADO, R.T.A. (coords.) Realização CAIXA. São Paulo: Páginas \& Letras- Editora e Gráfica, 2010.

HALLIDAY, S. Sustainable Construction. Burlington, USA: Butterworth-Heinemann, 2010.

LEED. Leadership in Energy and Environmental Design. LEED for New Construction \& Major Renovation, Version 2.2, Reference Guide. 2. ed., sep. 2009.

VIGGIANO, M.H.S. Edifícios públicos sustentáveis. 2010. Brasília: Senado Federal, Subsecretaria de Edificações Técnicas, 85p.

YIN, R.K. How to know whether and when to use case studies as a research method. In: Case Study Research: design and methods. 4. ed. Thousand Oaks: SAGE Publications. Applied Social Research Methods Series; v. 5. 2009.

ZEULE, L.O. Práticas e avaliação da sustentabilidade nos canteiros de obras. 2014. 263f. Dissertação (Mestrado em Estruturas e Construção Civil) - Universidade Federal de São Carlos, São Carlos, 2014. 


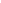

